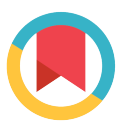

Check for updates

\title{
Imaging for Diagnosis and Monitoring of Cardiac Sarcoidosis
}

\author{
Ghazaleh Mehdipoor (MD) ${ }^{1, *}$, Sabahat Bokhari (MD) ${ }^{2}$, Martin \\ R. Prince $(\mathrm{MD}, \mathrm{PhD})^{3,4}$
}

${ }^{1}$ Cardiovascular Research Foundation (CRF), New York, NY, USA

${ }^{2}$ Division of Cardiology, New York Presbyterian Hospital and Columbia University Medical Center, New York, NY, USA

${ }^{3}$ Department of Radiology, Weill Cornell Medicine

${ }^{4}$ Department of Radiology, Columbia University College of Physicians and Surgeons, New York, NY, USA

* Corresponding author: Ghazaleh Mehdipoor (MD), Cardiovascular Research Foun-

DOI: $10.21859 / \mathrm{ijcp}-03204$ dation (CRF), New York, NY, USA.E-mail: Ghazaleh.mehdipoor@gmail.com

Submited: 10.04 .2018

Accepted: 18.04 .2018

Keywords:

Sarcoidosis

Heart Diseases

Diagnostic Imaging

Magnetic Resonance Imaging

Positron Emission

Tomography

(C) 2018. International Journal of

Cardiovascular Practice.

\begin{abstract}
Sarcoidosis is a granulomatous condition, primarily affecting the lungs and thoracic lymph nodes. Clinical cardiac involvement might occur in 2 to $5 \%$ of patients with sarcoidosis, and can be associated with serious complications including heart block, cardiomyopathy, ventricular arrhythmias, and potentially death. Timely diagnosis helps initiate treatment before cardiac damage becomes irreversible. In this brief review, we discuss imaging updates for diagnosis and monitoring of cardiac sarcoidosis.
\end{abstract}

\section{INTRODUCTION}

Sarcoidosis is a chronic granulomatous disorder. Although primarily affecting the lungs and thoracic lymph nodes, clinically it involves the heart in up to $5 \%$ of patients causing serious morbidity and mortality. $[1,2]$ Autopsy data suggest cardiac involvements in up to $25 \%$, emphasizing that there may be an underestimation due to the difficulty in diagnosis. $[3,4]$ Signs and symptoms depend on the site and extent of cardiac involvement, and include conduction abnormalities, and heart failure.[5] The diagnosis is usually made by existing recommendations, including those from the Japanese Ministry of Health and Welfare Criteria for Diagnosis of Cardiac Sarcoidosis (Revised 2006) and Heart Rhythm Society Expert Consensus Statement.[6, 7] Timely diagnosis can help direct specific treatments to ameliorate the disease course and avoid unnecessary interventions. Suggestive findings include increased myocardial wall thickness, regional wall motion abnormalities, systolic or diastolic dysfunction, and pericardial effusions on transthoracic echocardiography.[8] However, transthoracic echocardiography is not, in isolation, diagnostic for cardiac sarcoidosis. Historically, the diagnosis was made by endomyocardial biopsy. However, cardiac involvement could be patchy and missed by a single biopsy. Multiple biopsies are not feasible because of the increased procedural risks, and long-term complications such as tricuspid regurgitation.
$[9,10]$ Use of cardiac magnetic resonance (CMR) imaging, and positron emission tomography (PET) have redefined the timeliness of diagnosis, and have provided avenues for monitoring the response to treatment. Here we briefly review these imaging advances in diagnosis and monitoring of sarcoidosis. Diagnosis

Endomyocardial biopsy is the gold standard diagnostic method. However, focal involvement of the heart is one the limitations of biopsies. Increasing the sensitivity of biopsy by sampling multiple sites increases procedural risk. Thus, diagnostic utility of endomyocardial biopsy is limited. CMR imaging can evaluate the entire myocardium for sarcoid involvement and also evaluates cardiac structure, perfusion, and function.[11] CMR can show wall thickness abnormalities, edema, patchy involvement, and chronic fibrotic scar with delayed gadolinium enhancement. $[8,12] \mathrm{T}_{1}$-weighted images can demonstrate structural changes and $\mathrm{T}_{2}$-weighted images can detect the acute phase of inflammation.[13] Cine MR sequences assess wall motion abnormalities (hypokinesia or akinesia) due to scar or inflamation.[14] In the appropriate clinical context, the diagnosis of sarcoidosis is based upon the presence of patchy, subepicardial late gadolinium enhancement (LGE), which identifies fibrosis, or advanced disease.[14] MRI can also provide information about the mediastinum and possible 
extracardiac signs. Cardiac sarcoidosis without known or apparent extracardiac sarcoidosis has been reported previously, but is relatively rare.[15-18] Fluid sensitive sequences can also provide valuable information about the myocardial edema at earlier stages, but the role in the diagnosis of cardiac sarcoidosis is not clear.[7, 19] Since diagnosing sarcoidosis required gadolinium (typically a double dose), limitations include a risk of nephrogenic systemic fibrosis when GFR $<30 \mathrm{ml} / \mathrm{min}$ as well as allergic reactions to the gadolinium-based contrast agents. $[20,21]$ PET imaging is also commonly used to assess active cardiac sarcoidosis (Table 1).

PET requires a special patient dietary preparation to reduce glucose uptake by normal myocardium.[5] The patient must have a high protein, high fat, low carbohydrate diet for 24 hours prior to PET scanning. This reduces the glucose uptake by myocytes. Alternatively, unfractionated heparin could be administered to increase fatty acid availability. Upon arrival in nuclear cardiology laboratory, a rest $\mathrm{N}^{13}$ labeled ammonia PET is performed to identify myocardial perfusion defects. Then in the same setting F-18 Fluorodeoxyglucose (FDG) can be administered to identify sites of myocardial inflammation[22] as well as lymph nodes in the active phase of disease. Cardiac PET images are classified based on the perfusion defect and the corresponding FDG uptake into four categories of normal, early disease, progressive disease, and fibrous disease.[9, 23] The ability of FDG PET scan to identify inflammation can detect the disease at earlier stages, which is important for treatment before fibrosis happens.[9] Whole-body PET may be useful for detecting extracardiac involvement, especially in cases initially presenting with isolated cardiac sarcodosis.[17]

FDG PET can discover active cardiac sarcoidosis and is considered more sensitive than other radionuclide imaging tests. It assesses the hypermetabolic activity of myocardium due to inflammation. The most important advantage of FDG PET over MRI, is more accurate quantification of myocardial FDG uptake in sarcoidosis, which can assess response to therapy.[9] FDG is not accumulated in normal vascular structures. Neoplastic PET uptake could be differentiated since the uptake is more intense than other inflammatory diseases (including sarcoidosis).[24] On PET/ computed tomography (CT), the manifestations may include patchy or diffuse hypermetabolic activity. Cross-sectional imaging studies are complementary for precise localization of anatomic involvement.[24] FDG PET is also a useful imaging tool for diagnosis, evaluating disease activity, and monitoring the response to treatment in patients with sarcoidosis.[9] PET/ CT scan using F-18 sodium fluoride has been tested in recent years but does not appear to detect myocardial inflammation caused by suspected cardiac sarcoidosis.[25] Nuclear imaging tests for diagnosis of cardiac sarcoidosis are generally performed with thallium, technetium pyrophosphate, and gallium. Coronary artery disease should be differentiated from cardiac sarcoidosis by further pharmacological assessment usually with dipyridamole. Perfusion-inflammation mismatch happens in cardiac sarcoidosis. Alternatively, in those with newly discovered cardiomyopathy, coronary disease might be interrogated by other modalities, including cardiac catheterization. Gallium is sensitive for cardiac sarcoidosis. However, the currently available gallium scans are not sufficiently clear to differentiate between mediastinal and lung disease versus cardiac involvement with sarcoidosis. [26] A combined approach using FDG PET and CMR can assess inflammation, scar, fibrosis and wall motion abnormalities. Combined imaging modalities may help in confirmation of the diagnosis with higher confidence, better tissue characterization, and prognostication. Recently, guided biopsy with CMR or PET has been shown to be helpful. However, a negative biopsy does not exclude the diagnosis.[8] Real-time MRI guided biopsy has been reported to provide a better tissue characterization for guided biopsy from the patchy involvements. [27, 28]

\begin{tabular}{|c|c|c|c|}
\hline & $\begin{array}{c}\text { Transthoracic echocar- } \\
\text { diography }\end{array}$ & FDG PET & CMR \\
\hline $\begin{array}{l}\text { Test characteris- } \\
\text { tics/ protocol }\end{array}$ & $\begin{array}{l}\text {-Performed at beside with } \\
\text { cardiac ultrasound probes }\end{array}$ & $\begin{array}{l}\text {-Needs a special dietary preparation } \\
\text { in advance, with or without admin- } \\
\text { istration of intravenous unfraction- } \\
\text { ated heparin. Imaging is done after } \\
\text { about } 90 \text { minutes of FDG uptake. }\end{array}$ & $\begin{array}{l}\text { Cine short axis, } 4 \text {-chamber and } 3 \text {-chamber views; } \\
\text { Gadolinium to assess patchy and late enhancement as } \\
\text { well as } \mathrm{T}_{1} \text { and } \mathrm{T}_{2} \text { weighted images. }\end{array}$ \\
\hline $\begin{array}{l}\text { Role in diagnosis/ } \\
\text { prognosis / follow } \\
\text { up }\end{array}$ & $\begin{array}{l}\text {-Can help identify new } \\
\text { cardiomyopathy or } \\
\text { wall-motion abnormality, } \\
\text { ejection fraction, etc. }\end{array}$ & $\begin{array}{l}\text {-A sensitive tool to assess the hyper- } \\
\text { metabolic activity of myocardium } \\
\text { due to inflammation }\end{array}$ & $\begin{array}{c}\text {-Can identify patchy and Late gadolinium enhance- } \\
\text { ment in diagnosis of fibrosis }-\mathrm{T}_{1} \text {-weighted images are } \\
\text { useful for assessing structural changes and } \mathrm{T}_{2} \text {-weight- } \\
\text { ed images for acute phases of inflammation and } \\
\text { edema }\end{array}$ \\
\hline Strengths & $\begin{array}{l}\text {-Relatively inexpensive, } \\
\text { readily available, no } \\
\text { adverse effects }\end{array}$ & $\begin{array}{l}\text {-No immediate complications } \\
\text {-helpful to assess extracardiac } \\
\text { disease -A quantitative tool for as- } \\
\text { sessment of response-to-treatment }\end{array}$ & $\begin{array}{l}\text {-Can identify other cardiomyopathies or infiltrative } \\
\text { diseases with similar presentations - No ionizing radi- } \\
\text { ation -Prognostic utility -Provides valuable informa- } \\
\text { tion about the lungs and thoracic lymph nodes }\end{array}$ \\
\hline Limitations & $\begin{array}{l}\text {-Insufficient for definite } \\
\text { diagnosis }\end{array}$ & -Radiation & $\begin{array}{l}\text {-Some patients may have intracardiac devices that } \\
\text { are known to be incompatible with MRI -Length } \\
\text { of imaging is long for patients -Risk of nephrogenic } \\
\text { systemic fibrosis (if GFR }<30 \mathrm{ml} / \mathrm{min} \text { ) -Immediate } \\
\text { type allergic reactions }\end{array}$ \\
\hline
\end{tabular}




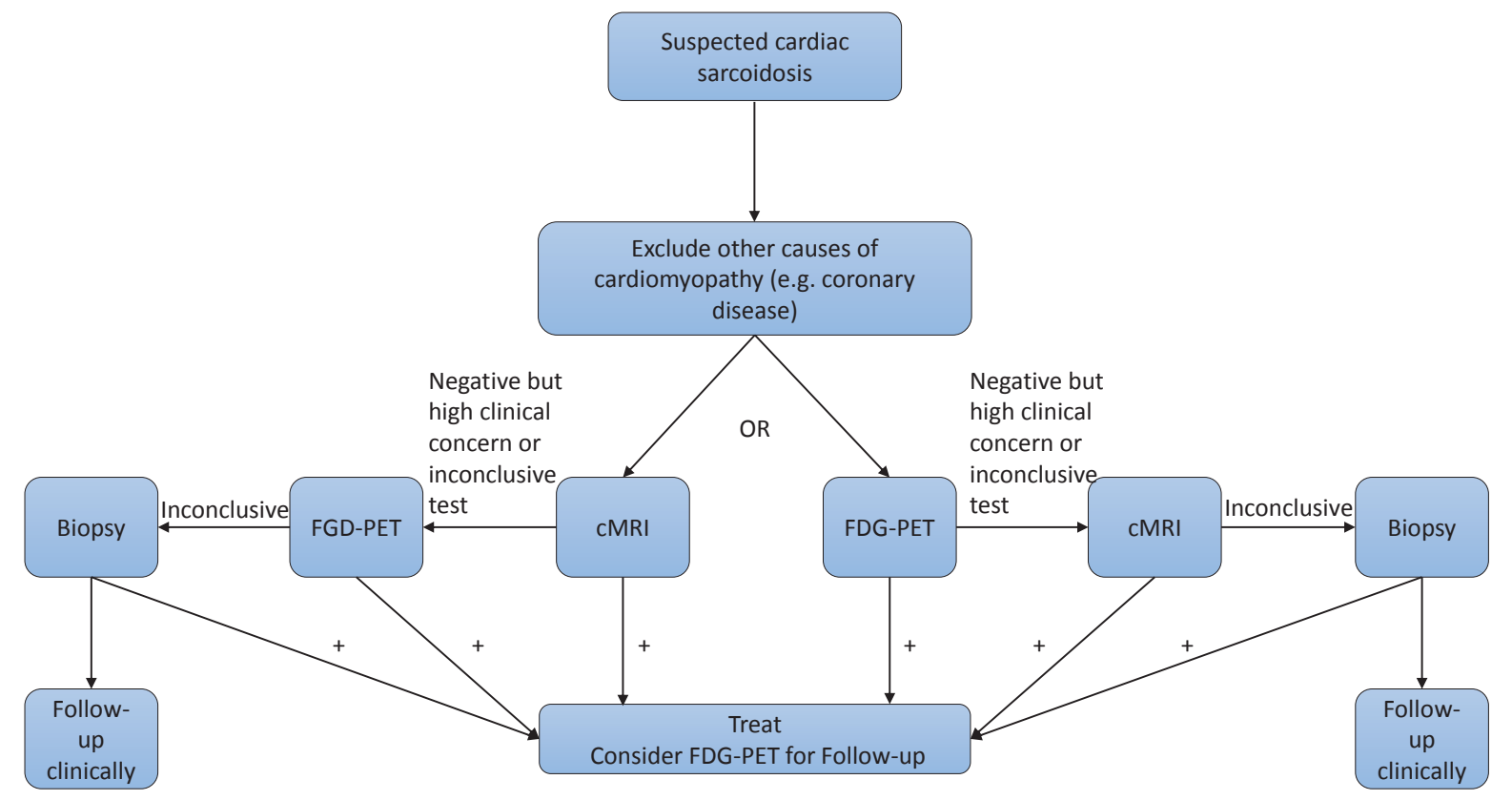

Figure 1: Flow Diagram for Diagnostic Evaluation for Suspected Cardiac Sarcoidosis

We should reemphasize that in patients with suggestive history and related cardiac findings, diagnosis of sarcoidosis should be considered once other common causes of cardiomyopathy, such as coronary disease, have been excluded and then an imaging modality would help for making the diagnosis (Fig 1).

\section{Prognostic Significance}

Initial echocardiographic assessment is helpful in prognostication and has been reported in a number of patients who are not responsive to immunosuppression therapy. $[5,15,29]$ In CMR, late gadolinium enhancement has also been reported to be an important prognostic factor and is associated with sudden cardiac death, implantable cardioverter-defibrillator (ICD) discharge, and ventricular arrhythmias in patients with systemic sarcoidosis.[2, $5,8,29-31]$ In addition, in a prospective study of cardiac sarcoidosis in 118 patients, FDG PET abnormality was associated with sudden cardiac death or ventricular tachycardia.[23] Clinically overt heart failure and impaired LV function portends dismal outcomes.[15]

\section{Monitoring Disease Activity}

PET imaging is an option to monitor the response to immunosuppressive therapy.[32] Serial FDG-PET can show normalization of tissue uptake after treatment which is also associated with improved outcomes, or may show cases resistant to treatment that might require adjusting therapies. $[33,34]$ The data about the follow-up of patients with CMR, is probably limited due to incompatibility of intracardiac devices such as defibrillators, commonly recommended for these patients, and MRI. However, in a recent study assessing the safety of MRI in 1509 patients with pacemakers or implantable cardio- verter defibrillator, no long term clinically significant adverse events were reported.[35] Therefore, it is likely that future studies can assess the potential impact of CMR on response to therapy, as well.

\section{CONCLUSIONS}

Cardiac sarcoidosis is a debilitating inflammatory cardiac myopathy that can lead into adverse outcomes including death. Although endomyocardial biopsy is the gold standard for diagnosis, existing and growing evidence and consensus statements[1] suggest that an algorithm of careful evaluation based on symptoms, signs, basic tests (such as electrocardiogram and echocardiogram) and advanced imaging modalities (such as CMR and FDG PET) can help make the diagnosis in most suspected patients. CMR and FDG-PET are complementary and provide valuable information for diagnosis and follow up. Hybrid imaging with PET-MR is a novel method to evaluate cardiac sarcoidosis and may improve the yield and timeliness of diagnosis.[36] Endomyocardial biopsy would be considered in selected cases, including those with inconclusive non-invasive test results, or those with high suspicion for the disease but without proven extracardiac disease.

\section{ACKNOWLEDGMENTS}

None.

\section{CONFLICTS OF INTEREST}

None declared.

\section{FUNDING}

No external funding was sought for this manuscript. 


\section{REFERENCES}

1. Birnie DH, Nery PB, Ha AC, Beanlands RS. Cardiac Sarcoidosis. J Am Coll Cardiol. 2016;68(4):411-21. DOI: 10.1016/j.jacc.2016.03.605 PMID: 27443438

2. Greulich S, Deluigi CC, Gloekler S, Wahl A, Zurn C, Kramer U, et al CMR imaging predicts death and other adverse events in suspected cardiac sarcoidosis. JACC Cardiovasc Imaging. 2013;6(4):501-11. DOI: 10.1016/i.jcmg.2012.10.021 PMID: 23498675

3. Iannuzzi MC, Rybicki BA, Teirstein AS. Sarcoidosis. N Engl J Med. 2007;357(21):2153-65. DOI: 10.1056/NEJMra071714 PMID: $\underline{18032765}$

4. Bokhari S, Lin J, Julien H. FDG-PET is a Superior Tool in the Diagnosis and Management of Cardiac Sarcoidosis. American College of Cardiology Latest in Cardiology 2018 [cited 2018 March 7]. Available from: http://www.acc.org/latest-in-cardiology/articles $/ 2017 / 04 / 10 / 08 / 43 /$ fdg-pet-is-a-superior-tool.

5. Birnie DH, Kandolin R, Nery PB, Kupari M. Cardiac manifestations of sarcoidosis: diagnosis and management. Eur Heart J 2017;38(35):2663-70. DOI: 10.1093/eurheartj/ehw328 PMID: 27469375

6. Health Mo. Guideline for Diagnosis of Cardiac Sarcoidosis: Study Report on Diffuse Pulmonary Diseases. Tokyo, Japan: Labour and Welfare, 1993.

7. Hulten E, Aslam S, Osborne M, Abbasi S, Bittencourt MS, Blankstein R. Cardiac sarcoidosis-state of the art review. Cardiovasc Diagn Ther 2016;6(1):50-63. DOI: 10.3978/j.issn.2223-3652.2015.12.13 PMID $\underline{26885492}$

8. Erthal F, Juneau D, Lim SP, Dwivedi G, Nery PB, Birnie D, et al. Imaging of cardiac sarcoidosis. QJ Nucl Med Mol Imaging. 2016;60(3):25263. PMID: 27225318

9. Skali H, Schulman AR, Dorbala S. 18F-FDG PET/CT for the assessment of myocardial sarcoidosis. Curr Cardiol Rep. 2013;15(4):352. PMID: 23544184

10. From AM, Maleszewski JJ, Rihal CS. Current status of endomyocardial biopsy. Mayo Clin Proc. 2011;86(11):1095-102. DOI: 10.4065 mcp.2011.0296 PMID: 22033254

11. Patel MR, Cawley PJ, Heitner JF, Klem I, Parker MA, Jaroudi WA, et al. Detection of myocardial damage in patients with sarcoidosis. Circulation. 2009;120(20):1969-77. DOI: 10.1161/CIRCULATIONAHA.109.851352 PMID: 19884472

12. Kuruvilla S, Adenaw N, Katwal AB, Lipinski MJ, Kramer CM, Salerno $\mathrm{M}$. Late gadolinium enhancement on cardiac magnetic resonance predicts adverse cardiovascular outcomes in nonischemic cardiomyopathy: a systematic review and meta-analysis. Circ Cardiovasc Imaging. 2014;7(2):250-8. DOI: 10.1161/CIRCIMAGING.113.001144 PMID: 24363358

13. Vignaux O, Dhote R, Duboc D, Blanche P, Dusser D, Weber S, et al. Clinical significance of myocardial magnetic resonance abnormalities in patients with sarcoidosis: a 1-year follow-up study. Chest. 2002;122(6):1895-901. PMID: 12475823

14. Satoh H, Sano M, Suwa K, Saitoh T, Nobuhara M, Saotome M, et al. Distribution of late gadolinium enhancement in various types of cardiomyopathies: Significance in differential diagnosis, clinical features and prognosis. World J Cardiol. 2014;6(7):585-601. DOI: 10.4330/ wic.v6.i7.585 PMID: 25068019

15. Kandolin R, Lehtonen J, Airaksinen J, Vihinen T, Miettinen H, Ylitalo K et al. Cardiac sarcoidosis: epidemiology, characteristics, and outcome over 25 years in a nationwide study. Circulation. 2015;131(7):624-32 DOI: 10.1161/CIRCULATIONAHA.114.011522 PMID: 25527698

16. Ikeuchi M, Kawano S, Ando M, Sekiya M, Kozai T, Urabe Y, et al. A case of biopsy-proven cardiac sarcoidosis without any other extracardiac manifestations. J Cardiol Cases. 2011;4(3):e138-e42. DOI: 10.1016/i.jccase.2011.07.006

17. Okada DR, Bravo PE, Vita T, Agarwal V, Osborne MT, Taqueti VR, et al. Isolated cardiac sarcoidosis: A focused review of an under-recognized entity. J Nucl Cardiol. 2016. DOI: 10.1007/s12350-016-0658-1 PMID: 27613395

18. Huitema MP, Swaans MJ, Grutters JC, Post MC. A case highly suspicious of isolated cardiac sarcoidosis. Neth Heart J. 2016;24(6):433-4. DOI: 10.1007/s12471-016-0837-3 PMID: 27167732

19. Zandieh S, Bernt R, Mirzaei S, Haller J, Hergan K. Image fusion between 18F-FDG PET and MRI in cardiac sarcoidosis: A case series. J Nucl Cardiol. 2016. DOI: 10.1007/s12350-016-0653-6 PMID: $\underline{27604109}$
20. Heshmatzadeh Behzadi A, Prince MR. Preventing Allergic Reactions to Gadolinium-Based Contrast Agents. Top Magn Reson Imaging. 2016;25(6):275-9. DOI: 10.1097/RMR.0000000000000106 PMID 27748715

21. Zou Z, Zhang HL, Roditi GH, Leiner T, Kucharczyk W, Prince MR. Nephrogenic systemic fibrosis: review of 370 biopsy-confirmed cases. JACC Cardiovasc Imaging. 2011;4(11):1206-16. DOI: 10.1016/j. jcmg.2011.08.013 PMID: 22093272

22. Kruse MJ, Kovell L, Kasper EK, Pomper MG, Moller DR, Solnes L, et al. Myocardial Blood Flow and Inflammatory Cardiac Sarcoidosis. JACC Cardiovasc Imaging. 2017;10(2):157-67. DOI: 10.1016/i jcmg.2016.09.023 PMID: 28109920

23. Blankstein R, Osborne M, Naya M, Waller A, Kim CK, Murthy VL, et al. Cardiac positron emission tomography enhances prognostic assessments of patients with suspected cardiac sarcoidosis. J Am Coll Cardiol. 2014;63(4):329-36. DOI: 10.1016/j.jacc.2013.09.022 PMID: 24140661

24. James OG, Christensen JD, Wong TZ, Borges-Neto S, Koweek LM. Utility of FDG PET/CT in inflammatory cardiovascular disease. Radiographics. 2011;31(5):1271-86. DOI: 10.1148/rg.315105222 PMID: 21918044

25. Weinberg RL, Morgenstern R, DeLuca A, Chen J, Bokhari S. F-18 sodium fluoride PET/CT does not effectively image myocardia inflammation due to suspected cardiac sarcoidosis. J Nucl Cardiol. 2017;24(6):2015-8. DOI: 10.1007/s12350-016-0525-0 PMID 27197820

26. Sekhri V, Sanal S, Delorenzo LJ, Aronow WS, Maguire GP. Cardiac sarcoidosis: a comprehensive review. Arch Med Sci. 2011;7(4):546-54. DOI: $10.5114 /$ aoms.2011.24118 PMID: 22291785

27. Lossnitzer D, Seitz SA, Krautz B, Schnackenburg B, Andre F, Korosoglou G, et al. Feasibility of real-time magnetic resonance imaging-guided endomyocardial biopsies: An in-vitro study. World J Cardiol. 2015;7(7):415-22. DOI: 10.4330/wjc.v7.i7.415 PMID: 26225203

28. Ratnayaka K, Faranesh AZ, Hansen MS, Stine AM, Halabi M, Bar bash IM, et al. Real-time MRI-guided right heart catheterization in adults using passive catheters. Eur Heart J. 2013;34(5):380-9. DOI: 10.1093/eurheartj/ehs189 PMID: 22855740

29. Kouranos V, Tzelepis GE, Rapti A, Mavrogeni S, Aggeli K, Douskou $\mathrm{M}$, et al. Complementary Role of CMR to Conventional Screening in the Diagnosis and Prognosis of Cardiac Sarcoidosis. JACC Cardiovasc Imaging. 2017;10(12):1437-47. DOI: 10.1016/j.jcmg.2016.11.019 PMID: 28330653

30. Hulten E, Agarwal V, Cahill M, Cole G, Vita T, Parrish S, et al. Presence of Late Gadolinium Enhancement by Cardiac Magnetic Resonance Among Patients With Suspected Cardiac Sarcoidosis Is Associated With Adverse Cardiovascular Prognosis: A Systematic Review and Meta-Analysis. Circ Cardiovasc Imaging. 2016;9(9):e005001. DOI: 10.1161/CIRCIMAGING.116.005001 PMID: 27621357

31. Bravo PE, Raghu G, Rosenthal DG, Elman S, Petek BJ, Soine LA, et al. Risk assessment of patients with clinical manifestations of cardiac sarcoidosis with positron emission tomography and magnetic resonance imaging. Int J Cardiol. 2017;241:457-62. DOI: 10.1016/j. ijcard.2017.03.033 PMID: 28318664

32. Shelke AB, Aurangabadkar HU, Bradfield JS, Ali Z, Kumar KS, Narasimhan C. Serial FDG-PET scans help to identify steroid resistance in cardiac sarcoidosis. Int J Cardiol. 2017;228:717-22. DOI: 10.1016/i. ijcard.2016.11.142 PMID: 27886616

33. Ahmadian A, Brogan A, Berman J, Sverdlov AL, Mercier G, Mazzini $\mathrm{M}$, et al. Quantitative interpretation of FDG PET/CT with myocardial perfusion imaging increases diagnostic information in the evaluation of cardiac sarcoidosis. J Nucl Cardiol. 2014;21(5):925-39. DOI: 10.1007/s12350-014-9901-9 PMID: 24879453

34. Ahmadian A, Pawar S, Govender P, Berman J, Ruberg FL, Miller EJ. The response of FDG uptake to immunosuppressive treatment on FDG PET/CT imaging for cardiac sarcoidosis. J Nucl Cardiol. 2017;24(2):413-24. DOI: 10.1007/s12350-016-0490-7 PMID: 27457527

35. Nazarian S, Hansford R, Rahsepar AA, Weltin V, McVeigh D, Gucuk Ipek E, et al. Safety of Magnetic Resonance Imaging in Patients with Cardiac Devices. N Engl J Med. 2017;377(26):2555-64. DOI: 10.1056/NEJMoa1604267 PMID: 29281579

36. Manoushagian SJ, Lakhter V, Patil PV. Multimodality imaging in the diagnosis and management of cardiac sarcoidosis. J Nucl Cardiol. 2017;24(1):29-33. DOI: 10.1007/s12350-016-0721-y PMID: 27837455 